\title{
Viagem à roda de Machado
}

\author{
Leonardo Vieira de Almeida ${ }^{1}$
}

RESUMO: No conto "Viagem à roda de mim mesmo", Machado de Assis dialoga não só com autores que trataram da caracterização de um novo tipo de viajante, o flâneur sentimental, mas estabelece um contraponto em sua releitura do termo der Doppelgänger. Assim, a hipótese deste ensaio é mostrar como a "viagem" se apresenta como desmitificação da corrente literária do fantástico e inscrição do próprio duplo ficcional.

ABSTRACT: In the short story "Viagem à roda de mim mesmo", Machado de Assis not only dialogues with authors who had dealt with the characterization of a new type of traveller, the sentimental flâneur, but he establishes a counterpoint in his reading of the term der Doppelgänger. Thus, the hypothesis of this essay is to show how the "journey" is presented as demythify of literary current of the fantastic and the inscription of his own ficcional double.

PALAVRAS-CHAVE: Conto machadiano; Viagem sentimental; der Doppelgänger; Psicanálise; Teoria da ficção.

KEYWORDS: Short story by Machado de Assis; Sentimental journey; der Doppelgänger; Psychoanalysis; Theory of fiction.

Como artista que praticamente nunca saiu dos limites do Rio de Janeiro, Machado de Assis construiu uma obra que, em muitas ocasiões, trata de paragens estrangeiras ou tem como tema a viagem. $\mathrm{Na}$ certeira expressão de Luciano Trigo, Machado se torna o "viajante imóvel", ocupado em transformar a "geografia" da cidade natal em um mapa onde se inscrevem suas impressões de leitura. E se a questão em pauta é a viagem, o escritor carioca, no prólogo da quarta edição das Memórias póstumas de Brás Cubas, apresenta uma arguta chave para a compreensão de seu processo ficcional, ao expor o seguinte ponto: “Toda essa gente viajou: Xavier de Maistre à roda do quarto, Garret na

1 Doutorando em Estudos de Literatura Brasileira na Pontificia Universidade Católica do Rio de Janeiro (PUC-Rio), desenvolve a pesquisa Grande Sertão: Veredas: pacto e promessa. Contato: leonardo33vieira@yahoo.com.br. O presente ensaio venceu o Concurso Machado de Assis (1908-2008), patrocinado pela Pontificia Universidade Católica do Rio de Janeiro (PUC-Rio). Obteve o $2^{\circ}$ lugar na categoria. 
terra dele, Sterne na terra dos outros. De Brás Cubas se pode talvez dizer que viajou à roda da vida" (ASSIS, 1971, p. 9).

Se Brás Cubas é o defunto autor que viaja "à roda da vida”, daí se infere uma das características fundamentais da prosa machadiana, um olhar de escritor muito preocupado em colher referências para uma viagem intima. Desse modo, se nas Memórias Machado apresenta sua divida como leitor a Maistre, Garret e Sterne, em outros de seus romances maduros, nos contos e crônicas, este mesmo problema se desdobra mediante distintos pontos de vista. Para corroborar tal fato, não é irrelevante lembrar que, em Dom Casmurro, Bento Santiago realiza um percurso em torno de si, périplo fadado a um aparente fracasso, na tentativa de unir as duas pontas da vida. Mas se ele não consegue realizar este intuito, por outro lado ata as páginas de sua própria história, concebendo um livro. Assim, tomando por base apenas esses dois romances, observa-se que o viajante, na ficção machadiana, encontra-se muitas vezes enclausurado no interior de seus desejos, o que o força a lutar com múltiplas máscaras de seu eu. Dessa maneira, o tributo que Machado presta aos autores citados no prólogo das Memórias torna possivel a compreensão desse problema, já que Laurence Sterne, particularmente em Uma viagem sentimental através de França e Itália (1768), concebe por meio de Yorick a figura do flâneur sentimental, cuja peregrinação interna, calcada na associação de idéias, torna o escritor de Tristram Shandy um "precursor de toda a psicologia literária contemporânea"2, no dizer de Jorge de Sena (SENA, 1963, p.

\footnotetext{
${ }^{2}$ Este lúcido ponto levantado por Sena se ampara em uma análise percuciente de determinada herança filosófica com a qual Sterne trabalha estilisticamente. Tal herança tem como característica um afastamento progressivo da metafísica, em que se acredita numa certa ordem do mundo regida pelo criador. Dessa forma, a crítica ao princípio da causalidade parece ser um estágio decisivo nesse processo. David Hume, em Investigação acerca do entendimento humano (1748), procura entender o homem como um ser muito mais prático e sensitivo do que racional. Para o pensador escocês, não haveria uma conexão necessária entre os fatos, como, por exemplo, na expressão "a pedra esquenta porque os raios do sol incidem sobre ela". Tomá-la como assertiva deriva de uma crença, inferida da "relação de fatos", que engloba, pelo hábito, determinadas ideias. No entanto, para Hume, não é possível saber, no caso explicitado, qual a origem da causa ("os raios de sol") que produz certo efeito ("a pedra esquenta"). Assim, as fontes e os princípios que regem os homens em suas operações constituem uma região obscura, designada pelo filósofo como "geografia mental". Não
} 
26). Ainda como precursores dos desvãos abertos pela psicologia, Xavier de Maistre realiza, por meio de um personagem formado de "alma" e "besta", uma perambulação nas fronteiras de seu quarto, em Viagem ao redor do meu quarto (1795); enquanto Almeida Garret, nas Viagens na minha terra (1846), defende que o homem é "o animal mais absurdo, o mais disparatado e incongruente que habita a terra" (GARRET, 1969, p. 156). Nesse sentido, a corrente da literatura que tem como tema a viagem encontra em Machado o leitor afinado com a problemática de um tipo de personagem que, dominado por contradições, se desloca em torno de si.

A esse respeito, é no conto "Viagem à roda de mim mesmo", publicado na Gazeta de notícias, em outubro de 1885, que o autor das Memórias trata uma vez mais desta questão. Já no próprio título é explícita a referência ao romance de Maistre, mas, neste caso, não é ao redor de seu quarto que viaja o bacharel Plácido, e sim em torno das exigências de sua personalidade cindida. O conto, em primeira pessoa, começa com Plácido lembrando fatos ocorridos há cerca de vinte e um anos, em 1864, quando tinha vinte e cinco anos. Tais fatos estão ligados ao desejo de desposar Henriqueta, a mais bela viúva daquele ano, segundo os habitantes da capital. Abrindo banca de advogado e morando numa casa de pensão, o personagem diz ser homem de parcos recursos financeiros e de poucos gastos, porque, como salienta: “as minhas despesas eram todas imaginativas. O reino dos sonhos era minha casa da moeda" (ASSIS, 1959, p. 1019).

Nesta confissão inicial, o bacharel revela uma faceta importante de sua personalidade, ou seja, a incapacidade de realização do desejo, pois este não ultrapassa a região do sonho. Em todas as ocasiões em que o personagem se sente preparado para confessar o amor por Henriqueta, não o consegue, e a possibilidade de a mulher romper os

tememos, dessa maneira, em sugerir a hipótese de que o pensamento de Hume, apesar de não investigá-la, delineia determinada região futuramente explorada pela psicanálise. Não caberá a Sigmund Freud estudar as fontes e princípios da "geografia mental" que nomeia inconsciente? Quanto a esta questão, iremos demonstrar mais adiante como Machado de Assis, relendo a tradição da narrativa de viagens, prenuncia literariamente esse campo de estudo. 
votos de viúva é sempre adiada. Numa das vezes em que se encontra a sós com ela, Plácido, sabendo que sua amada logo viajará para Petrópolis, procura se armar de coragem, mas, depois de algumas horas de relutância, acaba por se agarrar a uma piada contada por Henriqueta, terminando por dizer: "Abençoada anedota! Âncora dos anjos! Agarrei-me a ela, contente de escapar à minha própria vontade!" (ASSIS, 1959, p. 1021)

Observando com minúcia esta questão, podemos deduzir como Machado, alguns anos antes de fundamentais descobertas empreendidas pela psicanálise, concebe um conto que trata do que Freud toma como eixo basilar de suas teorias, a neurose. No caso de Plácido, o narrador-personagem busca, por meio de uma consulta a fontes filosóficas e literárias, procurar entender a estrutura que rege seu caráter, consubstanciada numa natureza dúplice. Comentando Spencer e Tylor, além do egiptólogo Gaston Maspero, o bacharel apresenta alguns versos atribuídos a Camões: "Entre mim mesmo e mim/ Não sei que se alevantou/ Que tão meu imigo sou” (ASSIS, 1959, p. 1021). Logo depois desta explanação, ficamos sabendo de um fato ocorrido na infância do personagem, que não consegue distingui-lo como alucinação ou realidade. Tendo ido ao quintal do vizinho colher frutas, o menino é duramente repreendido pelo pai. Após o incidente, à noite, deitado na cama, sem saber se acordado ou dormindo, vê diante de si uma figura idêntica a ele, que o censura de maneira violenta. A partir daí, torna-se continuamente perseguido pelo medo e, um dia, indo outra vez roubar frutas do vizinho, voltam as mesmas sensações. Contando como saiu da casa de Henriqueta depois do segundo encontro, sublinha que se sentiu novamente dois, um que arguia e outro que se desculpava, ouvindo toda sorte de imprecações, até que, mais tarde, achou-se reconciliado consigo, nutrindo o desejo de não deixar que Henriqueta viajasse antes de lhe propor casamento. ${ }^{3}$

\footnotetext{
${ }^{3}$ Podemos dizer que, distante cerca de vinte e quatro anos de um texto fundamental de Sigmund Freud, Notas sobre um caso de neurose obsessiva (1909), "Viagem à roda de mim mesmo" discute as consequências de uma repressão oriunda da instância
} 
Vê-se, dessa maneira, que Machado, ao conceber a figura de Plácido, põe em evidência uma temática cara à literatura, a questão do duplo que envolve, no seu cerne, as aspirações do desejo. De origem muito antiga, como atesta o teatro de Plauto (Anfitrião, Os Menecmas), o temário do desdobramento da personalidade desponta com força particular no século XIX, época de fundamentais descobertas no campo biológico e psíquico do ser humano. É justamente neste momento que adquire uma grande força a chamada literatura fantástica, caracterizada, no célebre estudo de Tzvetan Todorov, por sua intima ligação com a dúvida, ou seja, a impossibilidade de se discernir se a "estranheza" que irrompe no cotidiano deriva de uma desordem psíquica ou da influência do sobrenatural. Assim, o problema da duplicação de um "eu” em um “outro" se torna uma das chaves mestras mediante a qual se pode adentrar nesse terreno, como comprovam as obras de uma série de autores, para citar alguns: Edgar Allan Poe (“William Wilson”), Dostoiévski (“O sósia”), Guy de Maupassant ("Horla”), Robert Louis Stevenson ("O médico e o monstro"). No entanto, se nesses contos e novelas, segundo o pressuposto de Todorov, o fantástico deriva de uma situação natural progressivamente abalada pelo manifestar do insólito, outra será a maneira de tratar deste inaudito, em fins do século XIX e no despontar do século XX. Para o crítico búlgaro, "a Psicanálise substituiu (e por isso mesmo tornou inútil) a literatura fantástica” (TODOROV, 1975, p. 169).

De modo a clarificar essa idéia, Tzvetan Todorov defende que se até então o "homem comum" percebia seu cotidiano ser progressivamente invadido pelo insólito, passa a ocorrer uma ordem inversa, é o homem que se torna "fantástico". A recorrência do crítico a

paterna, a qual provoca em Plácido o complexo neurótico. No texto de Freud, resultado de uma análise que durou em torno de onze meses, a fonte do distúrbio do paciente encontra-se em um ódio pelo pai, que se acha recalcado no inconsciente. Desse modo, como uma das diversas manifestações do conflito, ocorre que, ao emergir a atração erótica pelo sexo oposto, surge uma espécie de delírio em que o "homem dos ratos", alcunha forjada por Freud para Herr Lanzer, crê que só poderá ter desejos sensuais de maneira livre se o pai morrer. No entanto, esse impulso homicida só consegue se manifestar pelo seu oposto, ou seja, o sintoma, que se traduz em Lanzer, sob inúmeras facetas, como autorrecriminação e gestos autodestrutivos. 
Freud remete ao célebre estudo "O estranho" (Das Unheimliche), de 1919, em que o escritor austríaco analisa a novela de E. T. A. Hoffmann, O homem da areia. A discussão, inicialmente, se volta para o problema do duplo por meio de uma abordagem etimológica das palavras heimlich e unheimlich. Segundo o autor, apesar de apresentarem vários significados contraditórios, os termos finalmente coincidem, já que heimlich como unheimlich "é tudo o que deveria ter permanecido secreto e oculto mas veio à luz" (SCHELLING apud FREUD, 1976, p. 282). Freud constata que o fenômeno do duplo evidencia, assim, um retorno constante do mesmo, "a repetição dos mesmos aspectos, ou características, ou vicissitudes, dos mesmos crimes, ou até dos mesmos nomes, através das diversas gerações que se sucedem" (FREUD, 1976, p. 293).

Quanto a este ponto, em "Viagem à roda de mim mesmo", a repetição desses "crimes" não deixa de perseguir Plácido, mesmo que sob "disfarces" distintos. Se em sua infância é o pai que o admoesta por ter roubado as frutas da casa vizinha, ainda na idade adulta o elemento cerceador retorna na figura de Veiga, um amigo deputado que vive na mesma casa de pensão onde reside o bacharel. Logo depois da última visita frustrada de Plácido à casa de Henriqueta, não obstante propor na imaginação a cena do casamento, o narrador, numa tirada agressiva, chega a afirmar: “'Sim, disse a mim mesmo; ela há de pagar-me o que me fez fazer ao Veiga'" (ASSIS, 1959, p. 1022). Em verdade, esse instinto repentino de vingança provém do fato de que em determinada noite, quando Plácido se preparava para ir a um sarau encontrar Henriqueta, achou o amigo, que lhe prometia o cargo de deputado e o salvara certa vez de uma dívida, adoentado. Entre ir ao encontro da mulher e ficar cuidando do Veiga, decide-se, instigado por três amigos do doente, a sair, sem que um exagerado sentimento do dever o acompanhe, interpondo-se a imagem de Henriqueta. No sarau, não consegue novamente comunicar seu pedido de casamento e, ao retornar à pensão, descobre o amigo em pior estado de saúde. No quarto, a sós consigo, chama-se de ingrato e tolo por deixar o companheiro arder em 
febre enquanto ia à caça de uns belos olhos. Caindo em uma poltrona, percebe outra divisão de si mesmo, dessa vez não física, como ele diz, mas moral, surgindo um Plácido imprecador e outro que se humilha. Conclui que o novo ressentimento contra Henriqueta não advém propriamente da situação, mas da "repetição do caso". Quatro dias depois, semelhante episódio volta a surgir, quando o narrador regressa de um jantar em casa da amada e ouve um morador da pensão dizer que o Veiga quase morrera devido à piora da moléstia, o que lhe provoca outra sensação de vergonha.

Como se vê, Plácido, ao mesmo tempo em que busca a realização do desejo com Henriqueta, sempre impedido pelo veto à fala, percebe não ser este o único mecanismo de repetição, e que, talvez, ele derive de uma causa original. Nesse caso, torna-se importante atentar para o fato de que o personagem assume uma posição distante dos eventos, pois conta uma história passada há mais de vinte anos. No entanto, esse afastamento no tempo não proporciona a Plácido a elucidação do misterioso processo de desdobramento, responsável pela duplicação tanto de seu corpo e psiquismo quanto de situações desagradáveis. O que se apresenta é o traçado de pistas, compondo uma espécie de teia de Ariadne que não desfaz o labirinto.

Seguindo essa linha, se apontamos a partilha de Machado com algumas descobertas empreendidas pelo pai da psicanálise, vale reforçar que, no caso de "Viagem à roda de mim mesmo", a discussão gira em torno de um personagem constantemente ludibriado pelo infortúnio, dado o qual, de acordo com Freud, é motor para o recrudescimento das exigências da consciência no campo da neurose. A esse respeito, Luiz Alberto Pinheiro de Freitas, no livro Freud e Machado de Assis: uma interseção entre psicanálise e literatura, assinala que, para o autor de $A$ interpretação dos sonhos, o ego, fustigado pela nãosatisfação do desejo, reconhece seu aspecto pecaminoso, curva-se ante o superego e o agente parental, os quais permanecem em constante vigília (FREITAS, 2001, p. 95). Ao final do conto de Machado de Assis, Plácido relembra uma última tentativa de expressar a Henriqueta seu 
desejo, que, no entanto, permanece apenas no pensamento. Saindo de sua casa, encontra por acaso um amigo de foro, quem começa a lhe contar sobre a questão de um inventário. Enquanto o escuta e acompanha, o bacharel vai pensando em como pela segunda vez perdeu sua bela Henriqueta, lembra-se dos episódios com o Veiga e das frutas da infância. Ao se deter nestas últimas, tem uma alucinação e vê sua pessoa no lugar do amigo, irritada e lhe dizendo impropérios. Mas logo percebe que se trata de um engano, ouve algo rir no ar e, levantando a cabeça para o céu, descobre que: "eram as estrelas, contempladoras remotas da vida, que se riam dos meus planos e ilusões, com tal força, que cuido rebentarem os colchetes (...)" (ASSIS, 1959, p. 1021).

Percebe-se, nesta última frase declarada por Plácido, o sarcasmo das estrelas, ou da vida, quanto às suas frustrações. Eclipsado pelo duplo, o narrador constata a impossibilidade de romper o círculo de repetições construído em torno de si mesmo. ${ }^{4}$ A este propósito, Clément Rosset salienta a ideia de que para haver o reconhecimento de si é preciso o exorcismo do "duplo", que funciona como um obstáculo para a sobrevivência do único e exige que este último não seja apenas ele mesmo (ROSSET, 1988, p. 67). Para o pensador francês, o único, ao ser devorado por sua própria imagem, recusa o real, húmus da vida. Plácido, dessa forma, vive sob o signo da imobilidade, pois encontra no real a mesma cópia de si, sem que lhe seja outorgada a liberdade de prescindir do "espelho".

\footnotetext{
${ }^{4}$ Nota-se que Machado de Assis, em "Viagem à roda de mim mesmo", afasta-se da categoria do fantástico, adentrando aquela "geografia" proposta por Todorov como uma espécie de banalização do estranho que atinge, em A metamorfose de Kafka, um determinado limite. Plácido pode ser tomado, assim, como o homem "fantástico", homem-enigma que busca nas remotas estrelas uma explicação para sua conduta. Nesse sentido, vale a pena lembrarmos o ensaio de Jorge Luis Borges, "Nathaniel Hawthorne", em Outras inquisições, no qual o escritor argentino declara que, com o conto "Wakefield", da coletânea Contos duas vezes contados, Hawthorne inaugura, no século XIX, nas letras da América, uma nova linha demarcatória. Assim, o personagem que dá título ao conto, cindido na figura dedicada do marido exemplar e do homem capaz de cometer um crime hediondo segundo a sociedade - permanecer durante vinte anos como voyeur da esposa, sem lhe dirigir uma única palavra -, prenuncia toda a literatura de Hermann Melville e Franz Kafka. Borges defende que "Wakefield" prefigura a leitura de Kafka, mas este muda e afina a leitura de "Wakefield".
} 
Sob esse aspecto, Machado de Assis, por meio do bacharel Plácido, retoma ou reduplica um personagem caro à sua fatura literária, aquele regido pelo índice do estéril. Já nas Memórias póstumas de Brás Cubas (1881), o defunto autor termina o livro com o epitáfio: "Não tive filhos, não transmiti a nenhuma criatura o legado da nossa miséria" (ASSIS, 1971, p. 173). No conto "Identidade", publicado dois anos depois de "Viagem à roda de mim mesmo", também na Gazeta de Noticias, onde volta a questão do duplo, um faraó, Pha-Nohr, idêntico ao escriba Bachtan, após uma existência de desalento e esterilidade, decide trocar de papéis com o sósia, e conclui que a vida nas classes menos favorecidas não deixa de ser infértil. Ele acaba, por fim, ao exigir do escriba o seu antigo lugar de faraó, sendo assassinado. Em Esaú e Jacó (1904), os gêmeos idênticos Pedro e Paulo vivem em torno de suas desavenças politicas e da infecunda Flora, que sucumbe sem que lhe seja possivel nem o amor de um, nem do outro, pois queria um terceiro par, a fusão dos dois.

Mas se a esterilidade se liga, desse modo, ao duplo dos personagens machadianos, porque estes não "concedem ao real", a obra do escritor carioca também aponta para outra via, esta fecunda, na sua obstinada repetição de um outro que não se quer o mesmo. Repetição que não se restringe apenas ao espelhamento de certos temas, personagens ou procedimentos de uma obra para outra, mas que se concentra à roda de um só perímetro geográfico. Em se tratando de "Viagem à roda de mim mesmo", além das referências a Sterne, Maistre e Garret, derivadas do próprio título, como já observado, e que remetem à temática dos viajantes na literatura, vem se unir a corrente do Doppelgänger, com a conseguinte desmitificação do fantástico. Daí, podemos inferir que, em paralelo ao desdobramento de Plácido, ocorre a inscrição do próprio duplo ficcional, ou seja, uma arqueologia de textos em que estes não se estruturam por superposição, mas se constituem como elementos disfarçados que repetem outros disfarces. Nesse sentido, vale lembrar que, para Gilles Deleuze, a repetição, 
psicanaliticamente falando, não é o retorno de algo original, mas é simbólica desde sempre, máscara e disfarce: "o símbolo, o simulacro, é a letra da própria repetição" (DELEUZE, 2006, p. 41). Para tanto, o filósofo francês reforça que um dos momentos decisivos da psicanálise foi aquele em que Sigmund Freud abandonou em alguns pontos a crença em acontecimentos reais da infância como termos últimos responsáveis pela constituição do reprimido, substituindo-os pela "potência do fantasma". E é justamente por causa desta potência que a repetição não deve ser compreendida como volta do idêntico, mas como diferença. Com respeito ao estatuto da ficção em Machado de Assis, podemos sugerir que o texto seria uma espécie de Narciso que se autodescobre nas águas da tradição da literatura, reproduzindo, no ponto de vista de Karlheinz Stierle, uma "alucinação involuntária", "a dupla ilusão da forma real e da forma real de um outro" (STIERLE, 2006, p. 14). O simulacro, assim, se configura como uma "duplicação enganosa", que pode ocupar o lugar de um autêntico original ou de um apenas fictício 5 . Machado, a nosso ver, opta por este procedimento, como pode ser constatado em sua fortuna enquanto crítico. Em "Instinto de nacionalidade", ensaio publicado em Nova York, em 1873, o autor, na luta por uma nova forma de expressão literária, chega a afirmar: "O que se deve exigir do escritor, antes de tudo, é certo sentimento íntimo, que o torne homem de seu tempo e do seu país, ainda quando trate de assuntos remotos no tempo e no espaço" (ASSIS, 1937, p. 131-132). A estratégia para dar universalidade a uma cultura de empréstimo, sendo um viajante à roda de si, foi, dessa forma, dialogar com a tradição não com o intuito de imitá-la, mas de "enganá-

\footnotetext{
5 Quanto a esta "duplicação enganosa" proposta por Karlheinz Stierle, e associada à obra de Machado, é importante sublinhar o ponto de vista de Marta de Senna. Analisando o conto "Viagem à roda de mim mesmo", a crítica observa o erro cometido pelo narrador em primeira pessoa, que ao procurar entender a coexistência de duas pessoas numa só, atribui a Camões versos que na verdade são de Bernardim Ribeiro. Entre as hipóteses levantadas pela autora para explicar esse fato, concordamos com aquela que diz ser capacidade dos narradores machadianos "rebaixar com graça passagens da literatura ocidental, descontextualizando-as e inserindo-as em contextos que jamais resvalam para o vulgar, graças ao humor elegante do autor". Cf. Marta de Senna, "A Bíblia de Mrs. Oswald ou os cochilos do Bruxo", p. 13.
} 
la": nem o fechar-se num pitoresco da linguagem nativa, nem a passividade diante do componente estrangeiro, mas o abrir-se para um outro reduplicado. Operação que teria em Proteu, deus do mar ovidiano, o espelho transubstancial que se finge em infinitas metamorfoses: "Há, ó mais corajoso dos homens, aqueles que foram transformados uma vez e para os quais esta forma nova é definitiva; há aqueles que têm o privilégio de passar por vários aspectos; é o caso para ti, habitante do mar (...)" (OVÍDIO apud STIERLE, 2006: 17).

\section{Referências bibliográficas}

ASSIS, Machado de. Esaú e Jacó. Rio de Janeiro: Globo, 1987. "Identidade". In: O conto de Machado de Assis. (Org.)

Sônia Brayner. 2. ed. Rio de Janeiro: Civilização Brasileira, 1981. . "Instinto de nacionalidade". In: Crítica literária. Rio de Janeiro - São Paulo - Porto Alegre: W. M. Jackson Inc., 1937. - Memórias póstumas de Brás Cubas e Dom Casmurro. São Paulo: Abril Cultural, 1971. . "Viagem à roda de mim mesmo". In: Obra completa, volume II: conto e teatro. (Org.) Afrânio Coutinho. Rio de Janeiro: José Aguilar, 1959.

BORGES, Jorge Luis. "Nathaniel Hawthorne". In: Outras inquisições. Trad. de Davi Arrigucci Jr. São Paulo: Companhia das Letras, 2007.

DELEUZE, Gilles. Diferença e repetição. Trad. de Luiz Orlandi e Roberto Machado. 2. ed. Rio de Janeiro: Graal, 2006.

FREITAS, Luiz Alberto Pinheiro de. Freud e Machado de Assis: uma interseção entre psicanálise e literatura. Rio de Janeiro: Mauad, 2001.

FREUD, Sigmund. "Notas sobre um caso de neurose obsessiva". In: Duas histórias clínicas ("O pequeno Hans" e "O homem dos ratos"). Edição standard brasileira das obras psicológicas completas de Sigmund Freud. Volume X (1909). Trad. de José Carlos Pavanelli. Rio de Janeiro: Imago, 1977.

. "O estranho". In: História de uma neurose infantil e outros trabalhos. Edição standard brasileira das obras psicológicas completas de Sigmund Freud. Volume XVII (1917-1919). Trad. de Eudoro Augusto Macieira de Souza. Rio de Janeiro: Imago, 1969.

GARRET, Almeida. Viagens na minha terra. Rio de Janeiro: Edições de Ouro, 1969.

HUME, David. Investigação acerca do entendimento humano. Trad. de Anoar Aiex. Os Pensadores. São Paulo: Nova Cultural, 2000.

MAISTRE, Xavier de. Viagem ao redor do meu quarto. Trad. de Armindo Trevisan. Porto Alegre: Mercado Aberto, 1998. 
ROSSET, Clément. O real e seu duplo: ensaio sobre a ilusão. Trad. de José Thomaz Brum. Porto Alegre: L\&PM, 1988.

SENA, Jorge de. "Laurence Sterne e 'A sentimental Journey' ". In: Novelas inglesas. São Paulo: Cultrix, 1963.

SENNA, Marta de. "A Bíblia de Mrs. Oswald ou os cochilos do Bruxo". Disponivel

$\mathrm{em}$ http://www.machadodeassis.net/download/A\%20B\%C3\%ADblia\% 20de\%20Mrs.\%200swald\%20ou\%20os\%20cochilos\%20do\%20Brux o.pdf. Acesso em: 02 ago. 2008.

STERNE, Laurence. "Uma viagem sentimental através de França e Itália". In: Novelas inglesas. Trad. de Anna Maria Martins. São Paulo: Cultrix, 1968.

STIERLE, Karlheinz. A ficção. Trad. de Luiz Costa Lima. (Orgs.) Carlinda Fragale Pate Nuñez e Francisco Venceslau dos Santos. Rio de Janeiro: Caetés, 2006.

TODOROV, Tzvetan. Introdução à literatura fantástica. Trad. de Maria Clara Correa Castello. São Paulo: Perspectiva, 1975.

TRIGO, Luciano. O viajante imóvel: Machado de Assis e o Rio de Janeiro de seu tempo. Rio de Janeiro: Record, 2001. 